\title{
As Direções em que Thor Arremessou sua Arma: Apontamentos Sobre a Etimologia e os Paralelos Mitológicos de Mjölnir
}

\author{
The Directions in which Thor threw his weapon: Appointments on Mjölnir's \\ Etymology and Mythological Parallels
}

\begin{abstract}
Victor Hugo Sampaio Alves ${ }^{1}$
${ }^{1}$ Mestre e doutorando em Ciências das Religiões pela Universidade Federal da Paraíba (UFPB) com orientação do Prof. Dr. Johnni Langer. Membro do Núcleo de Estudos Vikings e Escandinavos (NEVE), da Finnish Literature Society (SKS) e do Centro Internacional e Multidisciplinar de Estudos Épicos (CIMEEP). Estudo financiado pela Coordenação de Aperfeiçoamento de Pessoal de Nível Superior (CAPES). E-mail: victorweg77@gmail.com.
\end{abstract}

Recebido em 16 de março de 2020; Aceito em 21 de junho de 2020

\section{Resumo}

O principal objetivo do presente estudo é o de realizar um balanço das possibilidades etimológicas em torno da arma do deus nórdico Thor, mjölnir, geralmente descrita como sendo um martelo. Apresentaremos também as principais hipóteses a respeito de seu significado, que, basicamente, apontam para suas funções como raio arremessado e/ou objeto que esmaga e pulveriza. Mostraremos como mjölnir é pertencente a uma herança mitológica Indo-Europeia, elencando paralelos em outras mitologias que parecem reforçar essas conexões. Terminamos evidenciando influências desta concepção adotadas por povos Fino-Úgricos, como provável resultado de intercâmbio destes com povos Indo-Europeus.

Palavras-Chave: Thor; Mitologia Nórdica; Mjölnir; Indo-Europeu.

\begin{abstract}
The main objective of the present paper is to evaluate the etymological possibilities regarding Norse god Thor's weapon, mjölnir, usually described as a hammer. We are also going to present the main hypothesis regarding its meaning, which basically point to its functions as a thrown lightning bolt or an object which crushes and pulverizes. It will be demonstrated how mjölnir is a mythological inheritance from Indo-European, indicating parallels in other mythologies that seem to strengthen such connections. Finally, we are going to finish pointing out to possible influences of this conception among Finno-Ugric peoples, who must have borrowed it due to cultural exchanges from Indo-European peoples.
\end{abstract}

Keywords: Thor; Norse Mythology; Mjölnir: Indo-European. 
NEARCD: Revista Eletrônica de Antiguidade 2020, Volume XII, Número I - ISSN 1982-8713

Núcleo de Estudas da Antiguidade -NEA

Universidade do Estada do Rio de Janeiro

ISSN 1982-8713

\section{Introdução: Mjölnir e os Martelos na Escandinávia Medieval}

Mjölnir ou Mjolnir é a arma, comumente concebida como sendo um martelo, portada por Thor, divindade nórdica dos trovões. São ricas e diversas as menções a ela nas fontes literárias medievais, como nos poemas eddicos ${ }^{80}$ Hárbarđsljóđ e Prymskviđa, em narrativas da Edda em Prosa ${ }^{81}$ - sobretudo nos capítulos Gylfaginning e Skáldskparmál - e na Gesta Danorum ${ }^{82}$ de Saxo Grammaticus, além de citações também nas sagas islandesas. Conforme era de se esperar, por ser um dos símbolos religiosos da Era Viking que possui a maior quantidade de referências em obras literárias, mais de um significado é atribuído ao martelo ao longo desses materiais ${ }^{83}$ (LANGER, 2015, p. 302).

\footnotetext{
${ }^{80}$ Chamamos de eddicos os poemas pertencentes ao corpus conhecido como Edda Poética, nome dado a uma coleção de 29 poemas escritos em nórdico antigo, encontrados num manuscrito chamado Codex Regius. o Codex Regius é datado da segunda metade do século XIII, sendo tradicionalmente considerado como cópia de um manuscrito mais antigo que o antecedeu. Este teria sido redigido até aproximadamente 1220 d.C., mas foi perdido. Seguindo os passos típicos da tradição oral germânica, os poemas eddicos são anônimos e não oferecem quaisquer referências sobre as circunstâncias de sua produção ou seu autor. Grande parte das composições poéticas presentes na Edda são oriundas da Islândia, mas algumas delas foram feitas também em países como Noruega, Dinamarca, llhas Britânicas e de fontes germânicas continentais (LANGER, 2015, p. 147-147).

${ }^{81}$ Escrita em islandês antigo por volta de 1200 d.C., no Codex Upsaliensis sua autoria é atribuída claramente ao islandês Snorri Sturluson (LANGER, 2015, p. 143). A Edda em Prosa se mostra uma fonte primária inevitável para qualquer pesquisador que se proponha a estudar a mitologia ou a religião escandinava pré-cristã. Nos deparamos, neste caso, com uma obra única, original e que dá corpo ao mais denso e completo tratado sobre mitologia nórdica de toda a Idade Média, além das elucidações que traz a respeito da diç̧ão e métrica da poesia escáldica (FAULKES, 1995, p. xviii).

${ }^{82}$ A Gesta Danorum ("Feitos dos Daneses") foi escrita em latim pelo grande erudito dinamarquês Saxo Grammaticus, provavelmente entre os anos de $1188-1208$ d.C. A obra totaliza 16 tomos, sendo os 9 primeiros os que trazem relevantes informações, narrativas e descrições a respeito da mitologia e de costumes nórdicos pré-cristãos (FRIIS-JENSEN \& FISHER, 2015, p. xxix-xl)

83 Dentre eles, podemos elencar: suas propriedades rituais e mágicas, consagrando nascimentos, casamentos, mortes, funerais e juramentos; seu uso na demarcação e consagração de terras e propriedades, ou então até mesmo para encontrar ladrões; seu poder de propiciar a ressureição e a fertilidade da vida; seu simbolismo fálico; seu emprego mais óbvio e conhecido, como arma empunhada por Thor para defender os deuses e homens contra a raça dos gigantes e as forças do caos; e, por fim, como instrumento apotropaico que protegia o portador contra elementos naturais que representassem perigo (LANGER, 2015, p. 302).
} 
NEARCQ: Revista Eletrônica de Antiguidade 2020, Volume XII, Número I - ISSN 1982-8713

Núcleo de Estudas da Antiguidade -NEA

Universidade do Estada do Rio de Janeiro

ISSN 1982-8713

Na Escandinávia Medieval o martelo também está presente na cultura material ${ }^{84}$. Existem vestígios arqueológicos de inúmeros tipos de pingentes que constituem réplicas em miniatura do mjolnir $^{85}$, espalhados amplamente por todo o território escandinavo (PERKINS, 2001, p. 105), surgidos principalmente em meados do fim da Era Viking e que poderiam tratar-se, portanto, de uma resposta em oposição ao então crescente cristianismo ${ }^{86}$ (SIMEK, 2007, p. 219), apesar de não podermos tomar essa possibilidade como uma resposta homogênea desencadeada por toda a Escandinávia (NORDEIDE, 2004, p. 222). Ainda assim, é provável que as atribuições mágico-religiosas conferidas ao martelo tenham surgido na Escandinávia ainda durante a Idade do Bronze, conforme defende Hilda Davidson (1990, p. 80). A autora resgata uma inscrição em pedra ${ }^{87}$ desse período, onde uma figura humanoide ergue um martelo para o alto, em frente a duas outras figuras, provavelmente abençoando-as durante algum tipo de ritual de matrimônio.

\footnotetext{
${ }^{84}$ Há ainda ilustrações de Thor, inscritas em pedra, em que o deus segura um martelo, como nas pedras de Altuna (Suécia) e de Gosforth (Inglaterra).

${ }^{85}$ Não dispomos do espaço para apresentar e analisar os diversos achados arqueológicos das réplicas em miniatura de mjölnir, pois certamente esta é uma discussão que merece ser feita à parte e com a devida atenção. Em suma: vestígios arqueológicos dessas réplicas são encontrados por toda a Escandinávia e outras localidades do norte Europeu. A respeito do caso específico dos vikings, ver Nordeide (2002); Perkins (2001) e Davidson (1965); sobre a morfologia desses achados, ver Wamers (1999). Os martelos encontrados nas regiões da Finlândia e Estônia são discutidos extensivamente e colocados em perspectiva comparativa por Unto Salo (1990; 2006). É relevante citar também os machados em miniatura, encontrados por toda a região do Mar Báltico. Ainda que não tenham relação direta com Thor, eles estão conectados a divindades vernaculares do trovão de povos dessa região (KUCYPERA \& WADYL, 2011).

${ }^{86}$ Vale ressaltar que existem achados arqueológicos de moldes utilizados pelos ferreiros em que havia tanto o formato da cruz quanto o de mjölnir, apontando que esses artesãos, de certa forma, estavam prontos para atender desejos provenientes de ambas as demandas religiosas (DAVIDSON, 1990, p. 81; SIMEK, 2007, p. 219; GRAHAM-CAMPBELL, 1984, p. 114).

${ }^{87}$ A grande maioria dessas inscrições em pedra em território escandinavo, no entanto, manifesta figuras portando armas muito mais semelhantes a machados do que a martelos, geralmente em contextos explicitamente fálicos, e a própria autora ressalta que a lacuna de tempo entre a Idade do Bronze e a Era Viking é consideravelmente grande, sendo necessária cautela ao lidar com essa questão (DAVIDSON, 1990, p. 80). Há também a possibilidade de que o martelo nessas inscrições seja um símbolo de fertilidade e que, aliás, denotaria que a representação do martelo e do machado com essa conotação simbólica pode ser mais antigo que o próprio Thor (TURVILLE-PETRE, 1975, p. 84).
} 
NEARCD: Revista Eletrônica de Antiguidade 2020, Volume XII, Número I - ISSN 1982-8713

Núcleo de Estudas da Antiguidade -NEA

Universidade do Estada do Rio de Janeiro

ISSN 1982-8713

Nas fontes mitológicas, mjölnir é listado como uma das três valiosas posses de Thor $^{88}$. Talvez essa valorização se dê graças a seu uso enquanto arma para que o deus extermine os gigantes, o que coloca a função bélica de mjölnir em inegável evidência. Afinal, é justamente essa a sua utilidade que prevalece na mitologia ${ }^{89}$. Há ainda referências, apesar de mais pontuais e isoladas, a outros poderes de mjölnir que não os violentos, como quando Thor o manipula para ressuscitar seus bodes (Gylfaginning, p. 45) ou consagra, com ele, a pira funerária em que o deus Baldr seria cremado após sua morte (Gylfaginning, p. 49).

Outro detalhe mitológico relevante acerca de mjölnir diz respeito à sua criação ${ }^{90}$, sendo ela a razão de seu cabo ser peculiarmente tão curto. Além disso, Snorri Sturluson nos explicita que mjölnir produz raios e trovões ao ser arremessado ${ }^{91}$, sendo capaz de retornar para as mãos de Thor logo em seguida. Mas as fontes literárias nos revelam mais do que apenas os detalhes da criação mjölnir em específico: na Edda em Prosa

\footnotetext{
88 “Ele [Thor] tem três posses especiais. Uma delas é seu martelo Miollnir, bem conhecido pelos gigantes de gelo e gigantes da montanha ao ser erguido, o que não é surpreendente: ele esmagou vários crânios de seus pais e familiares" (Edda em Prosa, Gylfaginning, p. 22); "He [Thor] has also three special possessions. One of them is the hammer Miollnir, well known to frost-giants and mountain-giants when it is raised aloft, and that is not to be wondered at: it has smashed many a skull for their fathers and kinsmen" (Edda em Prosa, Gylfaginning, p. 22).

${ }^{89}$ Outros exemplos são em sua jornada para Útgarđa-Loki, em que Thor tenta por três vezes esmagar o crânio de um gigante com seu martelo (Gylfaginning, p. 39-40); quando o deus arremessa mjolnir em direção à sua mais poderosa inimiga, Jörmunganđr - a Serpente do Mundo - (Gylfaginning, p. 46-47; Hymiskviða); exterminando diversos gigantes presentes numa cerimônia de casamento (Prymskviða) ou ameaçando Lóki com seu martelo (Lokasenna).
}

${ }^{90}$ Mjölnir foi feito pelos anões Sindri e Brokkr. Enquanto o martelo estava em processo de forja, Lóki assumiu a forma de um mosquito e picou a pálpebra de Sindri, distraindo sua atenção (Edda em Prosa, Skáldskaparmál, 33).

${ }^{91}$ Essa afirmação tem se tornado alvo de crescentes polêmicas. Primeiramente, porque trata-se da única menção direta e explícita entre mjölnir (e também, incontornavelmente, de Thor) e os raios e trovões, sendo uma ocorrência isolada sem paralelos em outras fontes (sagas e poemas eddicos). Em outros contextos, as tempestades e tormentas causadas por Thor são muito mais consequências do impacto que as proporções colossais do deus e o deslocamento da sua carruagem causam no ambiente, do que manifestações de uma regência climática per se por parte do deus (TAGGART, 2017a) e o arremesso de seu martelo em analogia com raios e trovões parece se tratar mais de uma ocorrência em detrimento do contexto cósmico/atmosférico de suas batalhas (SCHJØDT, 2008, p. 221). O vínculo entre Thor e os trovões já foi analisado em pormenores (TAGGART, 2017b; 2015) e inclusive colocado em perspectiva comparativa em relação a outros deuses do trovão do norte Europeu (ALVES, 2019). 
NEARCD: Revista Eletrônica de Antiguidade 2020, Volume XII, Número I - ISSN 1982-8713

Núcleo de Estudas da Antiguidade -NEA

Universidade do Estada do Rio de Janeiro

ISSN 1982-8713

encontramos a explicação do surgimento do martelo enquanto ferramenta. Nesse material conta-se que, uma vez criados tempo e espaço, o que faltava era aquilo pertencente ao homem; a cultura. Então, uma forja foi instalada onde os primeiros patrimônios materiais começaram a ser criados. Os primeiros objetos a surgir foram as grandes pinças de forja e, a seguir, outras ferramentas, dentre as quais figura o martelo e que, juntas, possibilitaram que tudo fosse criado a partir do ouro. Snorri Sturluson cita o martelo como uma das primeiras ferramentas a surgirem, apontando que o aparecimento da Idade de Ouro mitológica pôde se concretizar somente por meio da criação das ferramentas de forja ${ }^{92}$. Portanto, talvez não seja coincidência o fato de que mjölnir seja justamente um martelo e que Thor, um dos deuses mais bélicos da mitologia nórdica, porte não uma arma comum como uma espada, lança ou machado, mas uma ferramenta para trabalho na forja: posicionando-se o martelo, ferramenta tão intrinsecamente ligada ao trabalho manual dos ferreiros e às atividades do mundo humano, nas mãos de Thor, era conectá-lo ao fundamento e surgimento da própria cultura, tornando-o uma espécie de herói cultural (LINDOW, 1994, p. 491-498).

Tendo apontado as inúmeras referências a mjölnir oriundas do contexto medieval, que abarcam desde as fontes literárias aos vestígios arqueológicos, pretendemos agora oferecer algumas das possibilidades que surgem ao longo da investigação de sua etimologia. Veremos que as origens de seu nome apontam para inúmeras direções onde, além de possíveis evidências de vínculos linguísticos, são encontrados também paralelos nas mitologias vernaculares pertencentes a outros povos - ainda que esses povos não fossem estranhos aos nórdicos e tenham mantido, com eles, intercâmbios culturais ao longo da história -. Contudo, antes apresentaremos

\footnotetext{
92 “Em seguida eles fizeram uma construção na qual instalaram forjas, e lá fizeram um martelo, pinças e uma bigorna, e partir deles todas as outras ferramentas; e então em seguida trabalharam o metal e a pedra e a madeira, e tão abundantemente aquele metal chamado ouro, e seus utensílios de casa e mobílias eram de ouro, e essa era é chamada de Era do Ouro" (Edda em Prosa, Gylfaginning, p. 19); "Next they made a building in which they set up forges, and there they made a hammer and tongs and anvil and from them all other tools; and next they worked metal and stone and wood, and so abundantly in that metal that is called gold, and their household implements and furnishings were of gold; and that age is called the Golden Age" (Edda em Prosa, Gylfaginning, p. 19).
} 
brevemente uma inusitada problemática que pretende abalar a certeza abordada há pouco: a de que mjölnir fosse um martelo.

\section{Uma Indagação Necessária: o Substantivo Hammar}

Ao longo de todas as fontes medievais literárias vernaculares, há ocorrência de apenas uma palavra invariavelmente empregada para definir mjölnir: o substantivo hammar (MOTZ, 1997, p. 329). Por semelhança fonética e ortográfica, os conhecedores da língua inglesa serão imediatamente remetidos à palavra hammer, cujo significado é martelo. De fato, inúmeros idiomas modernos da família germânica possuem, assim como o inglês, palavras semelhantes à hammar para designar essa ferramenta, como o norueguês hamar; o sueco hammare e o dinamarquês hammer, para citar apenas alguns; fora os paralelos existentes em línguas não-germânicas, que aderiram a palavras semelhantes por meio de contato cultural com estes, como o finlandês hamara (VRIES, 1977, p. 207).

No entanto, essas palavras análogas a hammar também servem para denotar, em seus respectivos idiomas, as palavras pedra, rocha (VRIES, 1977, p. 207). Já no século XIX, o folclorista Jacob Grimm registrou em seu Deutsche Mythologie que o significado primeiro de hamar (grafado por ele com apenas um $-m$ ) seria o de pedra ou rocha e que apenas em segunda instância esse substantivo era empregado para designar a ferramenta feita a partir desses materiais. Ainda segundo o autor, o idioma nórdico antigo teria preservado ambas os significados em sua palavra hamarr (GRIMM, 1882, p. 181).

Lembremos também que, ao longo dessas narrativas mitológicas, mjölnir é utilizado para determinadas ações que não parecem condizer com as executáveis por um martelo. Se, por um lado, por vezes é com ele que Thor esmaga o crânio de seus inimigos (o que condiz com a capacidade de esmagar dos martelos), por outro, ele também o arremessa em direção aos gigantes e, ainda mais curioso e surpreendente, é com mjölnir que o deus decapita ou ameaça decapitar seus oponentes. No poema 
NEARCD: Revista Eletrônica de Antiguidade 2020, Volume XII, Número I - ISSN 1982-8713

Núcleo de Estudas da Antiguidade -NEA

Universidade do Estada do Rio de Janeiro

ISSN 1982-8713

eddico Lokasenna, Thor ameaça decapitar Lóki com mjölnir ${ }^{93}$ e, na versão da pesca de Jörmunganđr narrada por Snorri Sturluson, Thor atira mjölnir contra a Serpente, decapitando-a94; o poeta escaldo Bragi chama Thor de "o decepador das noves cabeças de Prívaldi". ${ }^{95}$ Somemos a isso o fato de ser um tanto quanto estranho observar um deus marcial e atmosférico como Thor sendo tão constantemente retratado portando a ferramenta não de um guerreiro, mas de um artesão, ainda mais levando-se em conta que nada indique que o martelo, na Escandinávia Medieval, tenha excedido sua importância simbólica para além dos contextos metalúrgicos (MOTZ, 1997, p. 329-333).

Da mesma forma, os verbos que descrevem, nos materiais literários, as ações de mjölnir, permitem questionarmos se ele de fato seria um martelo: kljúfa, cujo significado inequívoco é partir, fender, dividir; também encontramos locuções verbais como drepa af, knýja ofan, ljósta af e ljósta ofan, sendo que as palavras af e ofan significam golpear, portando o sentido de remover algo e colocá-lo em outro lugar. O verbo drepa höfuð af, por exemplo, é usado em outros materiais para a ação de decapitar (MOTZ, 1997, p. 330). Encontramos, então, ações muito mais pertencentes a um machado do que a um martelo propriamente dito, embora ele por vezes também inquestionavelmente exerça 0 ato de esmagar.

\footnotetext{
93 “Então Thor chegou e disse: 'Fique quieta, criatura perversa, meu poderoso martelo/ Miollnir privará você de seu discurso;/arrancarei sua cabeça de seus ombros,/e então sua vida se extinguirá."' (Lokasenna, 57); "Then Thor arrived and said: 'Be silent, perverse creature, my mighty hammer/Miollnir shall deprive you of speech;/your shoulder-rock I shall strike off your neck,/and then your life will be gone."' (Lokasenna, 57). Preservamos a palavra hammer conforme consta na tradução para o inglês, mas deixando o leitor ciente de que no original lê-se hammar, substantivo que, conforme estamos vendo, seria passível de outras traduções. O mesmo se aplica para outras passagens em que trazemos traduções para o inglês constando o substantivo hammer.

94 “ $E$, justo no momento em que Thor estava segurando seu martelo e erguendo-o para o alto, o gigante [Hymir] manuseou sua faca de pesca e cortou a linha de Thor da amurada, e a serpente afundou no mar. Mas Thor arremessou seu martelo atrás dela, e dizem que ele arrancou sua cabeça próximo ao fundo do mar" (Edda em Prosa, Gylfaginning, p. 47); "And just at the moment when Thor was grasping his hammer and lifting it in the air, the giant fumbled at his bait-knife and cut Thor's line from the gunwale, and the serpent sank into the sea. But Thor threw his hammer after it, and they say that he struck off its head by the sea-bed" (Edda em Prosa, Gylfaginning, p. 47).

95 “Cleaver apart of prívaldi's nine heads" (Edda em Prosa, Skáldskaparmál, p. 73).
} 
NEARCD: Revista Eletrônica de Antiguidade 2020, Volume XII, Número I - ISSN 1982-8713

Núcleo de Estudas da Antiguidade -NEA

Universidade do Estada do Rio de Janeiro

ISSN 1982-8713

Portanto, retomando o significado original de hammar, é possível que mjölnir tivesse sido originalmente uma pedra ou ferramenta rudimentar feita a partir da pedra (algo que nos remete a uma antiga herança Indo-europeia ${ }^{96}$ ). Como não há indícios de que o martelo, nas sociedades nórdicas, tenha substituído outros instrumentos, fosse na heráldica, no uso cerimonial, na guerra ou no folclore, como ele terminaria substituindo a arma oriunda da Idade da Pedra portada originalmente por Thor? Parece improvável. Talvez mjölnir fosse visto nas mãos do deus como sendo uma pedra de raio ${ }^{97}$ que, com o passar do tempo e o avanço das tecnologias na sociedade nórdica, teria começado a ser concebido de outras formas, dentre as quais o machado feito de pedra é uma grande possibilidade. Afinal, ele condiz muito mais com os verbos empregados em relação ao substantivo hammar, além de ter sido de fato empunhado como arma pelos nórdicos, conforme nos revelam diversos achados arqueológicos espalhados por todo o território Germânico, datados desde o Neolítico (MOTZ, 1997, p. 334-336; 345-346).

Em última instância, pode-se levantar a hipótese de que, ao ser associada a Thor, a palavra hammar tenha passado a adquirir, na Escandinávia, um significado próprio,

\footnotetext{
${ }^{96}$ A palavra hammar para denotar rocha ou pedra não é um fenômeno observável apenas no mundo germânico, mas nos remete à uma origem Indo-Europeia. Podemos traçar a etimologia dessa palavra em islandês antigo provavelmente até a raiz * (a)kam-, cujo significado é 'pontudo', 'afiado' ou 'pedra'. Entre os desdobramentos dessa raiz também se encontram o sânscrito ásman-, 'pedra, rocha'; lituano akmuõ, 'pedra'; o grego ákmon-, bigorna; o eslavo antigo kamy, 'arma de pedra' e o avéstico asman-, 'pedra, céu' (VRIES, 1977, p. 207).

${ }^{97}$ As pedras de raio geralmente possuem um formato achatado e a cor escura, quase negra. Conforme 0 nome aponta, elas são associadas aos raios e, antigamente, aos deuses do trovão. Acreditava-se que elas caíam dos céus durante tempestades, mais especificamente trazidas pelos raios que, ao atingirem o chão, as depositavam no solo. Quando encontradas, essas pedras eram guardadas por possuírem propriedades mágicas e apotropaicas: elas protegiam a casa e evitavam que ela fosse atingida por raios; expulsavam criaturas e espíritos malignos; ajudavam na ordenha do leite, na feitura de manteiga, na fermentação de cereais e até mesmo na cura de vacas adoecidas, dentre outras coisas. A crença nas propriedades mágicas dessas pedras é identificada por toda a Escandinávia (Dinamarca, Noruega, Suécia, Finlândia), na Alemanha, Prússia, Espanha, Portugual e em lugares da África e Ásia (BLINKENBERG, 1911, p. 1-7). Recentemente tem sido encontrada uma grande quantidade de objetos líticos (fósseis marinhos, armas e utensílios pré-históricos, amoladeiras) em sepulturas nórdicas, apontando que, desde o Neolítico, poderia ter existido algum tipo de associação entre pedras com certos formatos especiais e a esfera celeste (RAVILIOUS, 2010).
} 
que não designasse um objeto bem definido do mundo dos homens. Assim, o substantivo hammar talvez apenas apontasse para o fato de que mjölnir era um objeto sagrado de significância e morfologia misteriosas. Por isso nenhum sinônimo é empregado nas fontes literárias para referir-se à arma de Thor (MOTZ, 1997, p. 345). Deixamos aqui essa provocação, demonstrando como é possível abalar a certeza de que mjölnir fosse um martelo. Como contraponto, John Lindow (1994) sustenta a defesa de que mjölnir seja concebido como tal, embora sem negar o significado de hammar como pedra, alegando haver, em Thor, a figura de um ferreiro primordial.

\section{MjöInir, Sua Herança Indo-Europeia e Paralelos em Mitologias Irmãs}

O étimo mjölnir não apenas possui paralelos em outras mitologias IndoEuropeias, como também se estende, ele mesmo, para inúmeras regiões dentro e fora do norte europeu. Ele remete à palavra $<*$ meldhniyos e é etimologicamente cognato ao galês mellt (raio) e ao russo mólnija (молния, raio) е mólot (молот, martelo) (PUHVEL, 1989, p. 201). Já no Proto-Nórdico a raiz de seu nome teria sido *melluniaR (SIMEK, 2007, p. 119) e, em Proto-Germânico, *melð uniyaz (WEST, 2007, p. 255-256).

Devemos levar em conta, no entanto, que ao tentarmos alcançar a raiz de mjölnir em qualquer desses proto-idiomas, estamos condenados a trabalhar com reconstruções filológicas e conjecturas linguísticas que visam apontar probabilidades da ocorrência e existência de palavras. Sendo assim, estamos o tempo todo pisando em terreno incerto, o que exige a busca por comprovações e paralelos para além das evidências linguísticas. Mantendo em mente essa ressalva, reproduziremos o alerta de Watkins (1995, p. 430), segundo quem a forma mjölnir não é demonstrativamente Indo-Europeia, apesar de que sua semântica, em contrapartida, o seja.

Afinal, diversas outras mitologias Indo-Europeias, distantes tanto geográfica quanto cronologicamente da Escandinávia Medieval, apresentam divindades atmosféricas de perfis heroicos cujas armas - martelos, machados, maças ou clavas estão relacionadas aos raios. Invocando alguns deles brevemente: o deus hindu Indra e 
NEARCD: Revista Eletrônica de Antiguidade 2020, Volume XII, Número I - ISSN 19882-8713

Núcleo de Estudas da Antiguidade -NEA

Universidade do Estada do Rio de Janeiro

ISSN 1982-8713

sua vájra ou vadhá; Mithra e sua vazra ou gada; o Feridun iraniano e sua maça gurz; na Grécia, Héracles/Orion/Poluphemos e sua ropalon, ou ainda Areithoos e seu korune (WATKINS, 1995, p. 430). Se, além disso, considerarmos os contextos em que as narrativas mitológicas posicionam tais divindades e suas armas, repararemos que é fazendo uso delas que essas divindades eliminam grandes inimigos como dragões, serpentes gigantes e outras bestas análogas, formando consideráveis paralelos com Thor exterminando Jörmunganđr com mjölnir (WATKINS, 1995, p. 230; DUMÉZIL, 1973, p. 66; TURVILLE-PETRE, 1977, p. 76; DAVIDSON, 1990, p. 90). No caso de Indra, o deus possuía uma arma que antecedia sua vájra - esta, associada aos raios -, justamente uma 'pedra dos céus' que os ferreiros primordiais o haviam confeccionado. Trata-se, possivelmente, de um machado de pedra e, se considerarmos a discussão anterior sobre o hammar para descrever mjölnir ser, na verdade, uma pedra, temos um paralelo relevante (MONTELIUS, 1910, p. 61).

Portanto, o forte vínculo entre as divindades atmosféricas e os martelos - ou armas análogas, como machados ${ }^{98}$ - não aparenta ser uma concepção única dos escandinavos, mas compartilhada por diversas mitologias Indo-Europeias. O deus sírio Baal, chamado pelos romanos de Jupiter Dolichenus, era representado segurando um machado de lâmina dupla em uma mão e raios na outra; Hefesto, deus grego relacionado à metalurgia, é retratado portando um machado duplo ou martelo, deus esse que, logo após nascer, caiu dos céus - numa possível alusão ao raio -; ruínas em Nimrud revelam deuses assírios numa espécie de procissão, onde é possível observar uma divindade carregando o machado em uma mão e, na outra, o raio (MONTELIUS, 1910, p. 60-65). Na região da Anatólia, o deus da tempestade Tarhunt/Tarhunzas é representado ostentando um raio de três terminações em sua mão, bradando um machado com a outra ${ }^{99}$ (WATKINS, 1995, p. 230). Outro aspecto curioso que parece

\footnotetext{
98 Para Montelius (1910, p. 65), quando se trata da simbologia da arma conferida aos deuses do trovão nas mitologias Indo-Europeias, o machado e o martelo denotam a mesmíssima coisa: os raios.

99 Não elencamos, aqui, os paralelos de mjölnir entre os povos bálticos, eslavos e celtas, pois trataremos especificamente destes mais adiante.
} 
NEARCD: Revista Eletrônica de Antiguidade 2020, Volume XII, Número I - ISSN 1982-8713

Núcleo de Estudas da Antiguidade -NEA

Universidade do Estada do Rio de Janeiro

ISSN 1982-8713

conectar os deuses Indo-Europeus relacionados à esfera atmosférica é o fato de que, em algum ponto antes de suas imagens antropomorfizadas, há indícios de que estes fossem concebidos como pássaros ${ }^{100}$ (KRAPPE, 1941, p. 241; 245; 255-257).

Se aceitarmos, portanto, as premissas de que: 1) mjölnir é um substantivo que mantém relação com étimos de outros povos Indo-Europeus que também designam o raio (galês mellt; russo молния/mólnija; antigo prússico mealde) (TURVILLE-PETRE, 1975, p. 81; VRIES, 1977, p. 390; SIMEK, 2007, p. 220; WEST, 2007, p. 254) ou até mesmo as nuvens (gótico milhma; sueco moln; dinamarquês mulm) (CLEASBY \& VIGFUSSON, 1874, p. 433) e que, 2) na mitologia, mjölnir era arremessado por Thor como sendo o próprio raio (WEST, 2007, p. 253-254; DAVIDSON, 1965, p. 5; WATKINS, 1995, p. 430), então, sem problema algum, seremos capazes de posicionar Thor e mjölnir dentro de um substrato Indo-Europeu onde existem inúmeros paralelos estruturais de deuses do trovão exterminando bestas com os raios, que são suas armas (LINDOW, 1994, p. 488).

Mas os paralelos etimológicos e mitológicos de mjölnir dentro de uma herança Indo-Europeia não se limitam a exemplos tão distantes da Escandinávia. Entre os povos com os quais os nórdicos mantiveram contato, as semelhanças são ainda mais intensas. Seu cognato no galês mellt (raio) aponta para probabilidades de analogias a mjölnir entre os celtas. No ramo celtibero, o deus gaélico Taranis - cujo nome, inclusive, é cognato de Thor ${ }^{101}$ - não é comumente retratado na iconografia ou nas narrativas

\footnotetext{
100 O autor parte da comparação entre o Zeus grego e o deus romano Picus, argumentando não apenas que o segundo era um pássaro, mas que ambos se tratavam, na verdade, da mesma divindade. $O$ autor extrapola sua argumentação até mesmo para o deus Perkūns que, no Báltico, está relacionado aos raios e trovões, dizendo que seu nome derivaria da raiz perk-, que deu a mesma origem ao latim Picus; portanto, isso faria dele também um deus que, antes de ser antropomorfizado, era visto como pássaro (KRAPPE, 1941 , p. 241-242; 245). Embora sua proposta seja inovadora e seus argumentos, linguística e filologicamente bem defendidos, a conclusão levantada carece de mais pesquisas, ainda que seja um assunto ainda inexplorado e repleto de possibilidades de pesquisa. Por outro lado, são muito mais fortes as evidências de divindades Fino-Úgricas do trovão pré-antropomorfizadas que teriam sido concebidas como 'pássaros de trovão' reinando os céus, algo presente também entre povos siberianos (SALO, 1990 p. 167-175; HOLMBERG, 1964, p. 439-441; SIIKALA, 2002, p. 49-52; 238).

${ }^{101}$ Taranis é cognato à raiz com - $u$ e, portanto, ao nome *taranu-, torann em Irlandês Antigo e ao Galês taran, ambos significando 'trovão'. O nome céltico taran é metatético à palavra tanar- (= germânico *thunar, que designa o trovão) (PUHVEL, 1989, p. 169).
} 
NEARCD: Revista Eletrônica de Antiguidade 2020, Volume XII, Número I - ISSN 1982-8713

Núcleo de Estudas da Antiguidade -NEA

Universidade do Estada do Rio de Janeiro

ISSN 1982-8713

portando um martelo ou arma similar; há vestígios, porém, de imagens suas segurando uma roda (como no caldeirão de Gundestrup) ou espirais em formato de $S$ que, muito provavelmente, são os próprios raios cintilantes que o deus controla (DUVAL, 1993, p. 224). Outro paralelo é identificado na figura de Dagda, este, divindade celta na região da Irlanda. No Ciclo Mitológico Irlandês ${ }^{102}$, sua participação se dá sobretudo em duas grandes batalhas cosmológicas contra os Fommoire ${ }^{103}$, os quais combate com sua clava de ferro que possui poderes análogos aos de mjölnir ${ }^{104}$ (SHAW, 2018, p. 99-103).

A etimologia endógena de mjölnir - ou seja, as propriedades desse étimo vistas de dentro de uma perspectiva germânica e norte-germânica - revela também uma gama de possibilidades dignas de investigação, ainda que por um caminho diferente. Pode ser que a arma de Thor esteja relacionada aos verbos mala (nórdico antigo) e malwjan (gótico), que significam esmagar, triturar, tornando-o, na forma substantiva mjölnir, em algo como aquele que esmaga/tritura (SIMEK, 2007, p. 220). Somado a essas cogitações podemos incluir também o verbo islandês mölva, que igualmente designa o ato de esmagar (TURVILLE-PETRE, 1975, p. 81) ${ }^{105}$. Portanto, a tradução do étimo mjölnir seria o esmagador (DAVIDSON, 1965, p. 5) e provavelmente fosse de fato essa a concepção vernacular que se tinha a respeito de sua função nos mitos ${ }^{106}$. Se por um lado

102 Dentro do estudo em mitologia gaélica, costuma-se dividir as narrativas em quatro ciclos: o Ciclo Mitológico, o Ciclo de Ulster, o Ciclo de Fianna e os Ciclos de Reis. O Ciclo Mitológico engloba uma série de acontecimentos em torno de povos semelhantes a deuses, que teriam migrado para o território da Irlanda, focando principalmente nos feitos dos Tuatha Dé Dannan, o panteão de deuses irlandeses dentre os quais encontra-se Dagda, que seria visto como uma espécie de chefe e protetor dessa tribo divina (MACKILLOP, 2016, p. 147).

${ }^{103}$ Adversários monstruosos de tamanho gigante, análogos aos jötnar da mitologia nórdica, combatidos por Thor (SHAW, 2018, p. 99).

${ }^{104}$ Assim como mjölnir, a clava de Dagda não é apenas utilizada como arma, mas como instrumento detentor do poder de ressuscitar os mortos e modificar o ambiente em seu entorno (SHAW, 2018, p. 103104).

105 Embora, ao apontar a possibilidade de conexão entre mjölnir e estes verbos que significam "esmagar", o autor também não descarte possíveis relações com substantivos que designam o raio, como o galês mellt e o russo mólnija (TURVILLE-PETRE, 1975, p.81).

${ }^{106}$ Apesar de que apontamos para a existência de basicamente duas vertentes de entendimento em torno do verbo que, nas narrativas mitológicas, ilustra de maneira frequente as ações de mjölnir: ljósta. John Lindow (1994, p. 487) defende que o verbo designa o ato de golpear, bater, atingir, enquanto que Lotte 
NEARCD: Revista Eletrônica de Antiguidade 2020, Volume XII, Número I - ISSN 19882-8713

Núcleo de Estudas da Antiguidade -NEA

Universidade do Estada do Rio de Janeiro

ISSN 1982-8713

considerarmos que, em uma considerável parte das narrativas de que dispomos, Thor elimina seus inimigos esmagando-os com mjölnir ${ }^{107}$ e, por outro, as conexões etimológicas entre o nome desse artefato e os verbos agora abordados, denotadores do mesmo tipo de ato, então pode-se defender que as habilidades de pulverizar e moer estivessem no centro do entendimento vernacular sobre mjölnir (TAGGART, 2015, p. 190).

Caso consideremos as conotações pulverizadoras e/ou atmosféricas de mjölnir, encontraremos paralelos presentes entre os povos bálticos ${ }^{108}$ e eslavos. Antes de mais nada, vale ressaltar que, nessas regiões, os próprios nomes das divindades portadoras de armas análogas ao mjölnir de Thor designam, assim como no caso do deus nórdico, o trovão: na Lituânia, Perkunas; na Letônia, Pērkons; na Antiga Prússia, Percunis. Do século XIII em diante existem inúmeros relatos a respeito dos prússicos, lituanos ou letões adorando um deus dos trovões ${ }^{109}$ e tempestades cujo nome gira em torno de variações como Percunus, Percunos, Pirchunos, Perkuns, Parcuns ou Pargnus. Esse fenômeno também é observável entre as divindades eslavas, cujos nomes igualmente significam trovão: Perún na região russa; o Piarun bielorrusso; o Parom eslovaco; o polonês Piorun e, em tcheco, Peraun (WEST, 2007, p. 239; 242). Além disso há, entre essas línguas balto-eslávicas, palavras cognatas a mjölnir que, da mesma forma,

Motz (1997, p. 330), conforme abordamos anteriormente, designaria o ato de decepar - o que converge com a perspectiva defendida pela autora de que mjölnir se tratava de um machado -. Por conta disso, há certos casos em que não é possível saber qual é a função sendo exercida pela arma de Thor, ainda que na maioria dos casos o contexto nos deixe claro do que se trata.

107 Isso acontece quando, ao apresentar Thor, Snorri Sturluson alega que sua arma é famosa por esmagar os crânios de seus inimigos (Edda em Prosa, Gylfaginning); em sua viagem para Útgarđa-Loki, em que Thor desfere três golpes na cabeça do gigante Skrymir (Edda em Prosa, Gylfaginning); e também nos poemas eddicos Hymiskviða e Prymskviða.

108 Por "bálticos" nos referimos, aqui, aos povos Indo-Europeus que habitaram a região leste do Mar Báltico, como os lituanos, letões e poloneses, não abarcando, portanto, os balto-fínicos (finlandeses, estonianos, ingrios, etc.): estes, apesar de também habitarem essa região, são povos Fino-Úgricos.

109 Ainda nos idiomas lituano e letão modernos, as palavras perkūnas e pērkons, respectivamente, designam o fenômeno do trovão (WEST, 2007, p. 239). 
NEARCD: Revista Eletrônica de Antiguidade 2020, Volume XII, Número I - ISSN 1982-8713

Núcleo de Estudas da Antiguidade -NEA

Universidade do Estada do Rio de Janeiro

ISSN 1982-8713

denotam o trovão: o antigo prússico mealde; o bielorrusso maladna; o russo mólnija e o antigo russo eclesiástico mlŭniji (WATKINS, 1995, p. 429).

Essas divindades do trovão também portavam armas análogas a mjölnir. No caso eslavo, por exemplo, há uma menção de Procópio, em seu De bello Gothico ${ }^{110}$, a respeito de como a divindade suprema desses povos tratava-se de Perun, deus dos raios e trovões; ele é ainda citado muito posteriormente, na Crônica Primária Russa ${ }^{111}$, onde é relatada a existência de uma estátua sua, colocada em Kiev a mando do príncipe Vladimir I, feita em prata e ouro e portando um machado (PUHVEL, 1989, p. 234; MONTELIUS, 1910; p. 60). A arma de Pērkons, deus do trovão cultuado pelos letões, era uma maça chamada milna, originária da palavra báltica *mildnā; ambos os étimos estão relacionados, por um lado, a uma série de palavras indo-europeias que significam martelo ou marreta (latim malleus, russo mólot, bretão mell, lúvio maldani-) e, por outro - como era de se esperar - a outras palavras, aqui já abordadas, que designam os raios (galês mellt, russo mólnija, antigo prússico mealde, antigo russo eclesiástico mlŭniji). A milna $^{112}$ de Pērkons, portanto, é cognata de mjölnir e apresenta as mesmas duas possibilidades de universos semânticos: a noção de esmagar, pulverizar e a de serem denotadores do raio (WEST, 2007, p. 253-254).

\footnotetext{
110 Procópio de Cesareia foi um historiador do Império Bizantino do século VI, responsável por escrever, dentre outras obras, a História das Guerras, dividida em 8 tomos. Os 4 tomos finais, especialmente interessantes para nós, cobrem as Guerras Góticas, trazendo algumas menções sobre tribos eslavas (CAMERON, 2005, p. 134-143).

${ }^{111}$ A Crônica Primária Russa, conhecida também como Crônica dos Anos Passados ou Crônica de Nestor, foi escrita em Kiev, no início do século XII. Do ponto de vista histórico e religioso, consiste na obra de maior extensão e importância sobre os Rus - escandinavos da região da Suécia - que chegaram a Kiev. A Crônica proporciona informações indispensáveis a respeito de fatos históricos, dos cultos religiosos e panteão de deuses de várias das tribos eslavas de então (LA PUENTE, 2017).

112 É importante notar que a milna de Pērkons nem sempre é descrita como um martelo. Outras vezes o deus é descrito portando uma lança, espada, flechas ou até mesmo projéteis de pedra (WEST, 2007, p. 254). Ainda assim, considerando que o próprio mjölnir de Thor é passível de ser questionado como sendo morfologicamente um martelo - conforme vimos a respeito do substantivo hammar - (MOTZ, 1997, p. 334-336; 345-346) o que nos interessa e é digno de atenção são os paralelos etimológicos e mitológicos: ambos os étimos milna e mjölnir relacionam-se aos raios e ao ato de esmagar, sendo os dois, ainda por cima, armamentos que são posses dos respectivos deuses do trovão de cada mitologia.
} 
NEARCD: Revista Eletrônica de Antiguidade 2020, Volume XII, Número I - ISSN 19882-8713

Núcleo de Estudas da Antiguidade -NEA

Universidade do Estada do Rio de Janeiro

ISSN 1982-8713

Uma das possibilidades etimológicas de mjölnir, então, seria algo como aquele que pulveriza ou o pulverizador, conferindo destaque à sua habilidade de esmagar. Os paralelos entre ele e a arma de Pērkons podem ser levados ainda mais adiante: milna também é uma palavra empregada para designar o cabo dos antigos moinhos ${ }^{113}$, moinhos cuja função, conforme sabemos, é justamente a de pulverizar alimentos. Há, inclusive, uma concepção lituana de que o barulho do moinho em movimento assemelha-se ao som do trovão (FROG, 2014, p. 129). Curiosamente, milna e mjölnir também mantém relações com palavras indo-europeias que designam moinhos, como o grego $\mu 3 \lambda \eta$ e os verbos molare em latim e molót em russo, utilizados para descrever as ações realizadas pelo moinho (WEST, 2007, p. 254). Pode ser que a concepção indoeuropeia de que as divindades atmosféricas portam armas com capacidade esmagadora nos remetam a um fenômeno cultural, linguístico e mitológico muito mais complexo do que imaginamos.

Analisando o étimo mjölnir por outros ângulos, notamos que as duas concepções em seu entorno - como instrumento esmagador ou como raio - não são excludentes. Muito pelo contrário, elas parecem conectar-se de alguma maneira, como vimos acima, na concepção lituana que enxergava conexões entre o barulho do moinho e o do trovão. Mjölnir pode estender suas relações até o nórdico antigo mjöll (neve fresca) e ao islandês mjalli (cor branca, ideia de algo que reluz) e, assim, Simek (2007, p. 220) defende que o nome de mjölnir seja traduzido como arma brilhante de raios, viés interpretativo com o qual Lotte Motz (1997, p. 343) se alinha; nessa perspectiva, a arma de Thor poderia ser enxergada como o próprio raio.

No entanto, para Declan Taggart (2015, p. 190) a função primária de mjölnir nas narrativas mitológicas é claramente a de arma letal que justamente esmaga - ou

\footnotetext{
${ }^{113}$ Embora não seja o objetivo de seu estudo, Frog (2014, p. 129) menciona a possibilidade de haver uma crença, fruto de herança Indo-Europeia, relacionando os trovões ao barulho dos moinhos, conduzidos por bodes pertencentes a uma divindade suprema dos céus. A relação entre moinhos, trovões e bodes é encontrada em povos germânicos, bálticos e gregos. Sobre a questão do moinho mitológico entre os finlandeses e nórdicos, ver Tolley (2009, p. 290-301).
} 
pulveriza - o crânio de seus inimigos, negando que sua etimologia possa inferir que seu arremesso fosse visto como o lançar de raios por parte de Thor. As perspectivas, contudo, não são necessariamente excludentes, sendo plausível que mjölnir possa significar pulverizador e designar, simultaneamente, os raios: talvez as fontes mencionem "golpes" oriundos do martelo, e não diretamente os raios, porque a compreensão vernacular desses povos que apresentavam divindades atmosféricas fosse justamente a de que os trovões "esmagam" (BLINKENBERG, 1911, p. 60).

De qualquer maneira, há inúmeras evidências, conforme vimos, que permitem associarmos mjölnir aos raios, seja na crença de que estes se tornavam as pedras de raio encontradas no chão, sejam as narrativas mitológicas que fazem alusão ao martelo sendo atirado contra os inimigos de Thor, ou, ainda, a evidência que resgatamos, por meio da mitologia comparada, de deuses do trovão que, com suas respectivas armas, as arremessavam em movimento análogo ao dos raios. Há paralelos bálticos, celtas, gregos, hindus, iranianos e eslavos desse fato, entre outros (WEST, 2007, p. 255-256; BLINKENBERG, 1991, p. 61; WATKINS, 1995, p. 430; MONTELIUS, 1910, p. 60-61; FROG, 2014, p. 129-130; PUHVEL, 1989, p. 201; 234). Ainda assim, os paralelos não se dão apenas entre os nórdicos e outros Indo-Europeus, mas também entre outros povos, embora em número consideravelmente menor. Sendo assim, convém abordarmos, a nível ilustrativo, algumas ocorrências de paralelos do étimo mjölnir entre os povos FinoÚgricos.

\section{Analogias Outras: Conexões Fino-Úgricas}

Mesmo os Fino-Úgricos que mantiveram intenso intercâmbio cultural com os nórdicos ao longo da história, como os finlandeses e sámis, possuem uma outra concepção a respeito das divindades do trovão. Ela difere dos vigorosos deuses atmosféricos Indo-Europeus, descritos com barbas vermelhas, olhares furiosos e um apetite insaciável (MONTELIUS, 1910, p. 61; DAVIDSON, 1990, p. 73; WEST, 2007, p. 250); os deuses Fino-Úgricos do trovão tendiam a ser concebidos como anciões, algo 
NEARCD: Revista Eletrônica de Antiguidade 2020, Volume XII, Número I - ISSN 1982-8713

Núcleo de Estudas da Antiguidade -NEA

Universidade do Estada do Rio de Janeiro

ISSN 1982-8713

acusado por seus próprios nomes: na Finlândia, a divindade atmosférica atendia pelos nomes Isänen (pequeno pai) e Ukko/Ukkonen (pequeno ancião) e, na Estônia, por Äi (velho homem) ou Äikene (pequeno velho); entre os mokshas, seu nome era At'ham, derivativo de $a t^{\prime} a$, que significa avô (HOLMBERG, 1927, p. 388). As armas que portavam eram, também, costumeiramente diferentes, constituindo principalmente arcos e flechas (HOLMBERG, 1927, p. 230-231).

Ainda assim, podemos identificar a existência de martelos relacionados ao culto dos deuses do trovão entre esses povos, bem como possíveis paralelos ao mjölnir de Thor, a começar pelo fato de haver cognatos ao próprio nome do deus escandinavo entre os Fino-Úgricos do norte da Escandinávia e do Báltico: o nome do deus sámi dos trovões, Horagalles, teria vindo de Pórr karl (velho Thor); bem como o Tuuri, da Finlândia e Carélia e o estoniano Tooru (VRIES, 1956, p. 115; KULMAR, 2005, p. 24-28; FROG, 2011, p. 80). A relação entre as divindades atmosféricas e os martelos é notada especialmente entre os sámis, que representavam seus deuses do trovão ${ }^{114}$, tanto em ilustrações nas superfícies de tambores quanto em estátuas, segurando um martelo em cada mão (HOLMBERG, 1927; 230-231; BLINKENBERG, 1991, p. 61-63; ALVES, 2019, p. 104-109) com os quais, acreditava-se, controlava os ventos e tempestades ou então eliminava criaturas malignas (TURVILLE-PETRE, 1975, p. 84).

Já citamos anteriormente que o próprio substantivo hammar chegou até os finlandeses e acabou por ser inserido em seu vocabulário na forma hamara, preservando o seu significado (VRIES, 1977, p. 207). Há ainda outras prováveis importações Indo-Europeias, por parte de povos Fino-Úgricos, dos nomes dessas armas portadas pelos deuses do trovão, embora, nesse caso, não remetam diretamente ao

\footnotetext{
${ }^{114}$ Nas fontes primárias são conferidos constantemente diversos nomes às divindades sámi dos trovões. Considerando que existem diversas etnias sámi, espalhadas desde o norte da Noruega até a Península de Murmansk, na Rússia, passando por Suécia e Finlândia, todas apresentando seus respectivos idiomas (muitas vezes não mutuamente compreensíveis) e peculiaridades culturais, não adotamos a perspectiva de que se tratem de variações de nomes abarcando uma mesma divindade pan-sámi. Os nomes conferidos a esses deuses do trovão variam marcadamente de acordo com a região tratada pela fonte: Horagalles/Hovrengaellies (região sul), Tiermes (região nordeste), Aijeke (regiões centro-oeste, noroeste) e abarcam, a nosso ver, divindades distintas. A esse respeito, ver Frog (2017).
} 
étimo mjölnir. A vájra- do deus hindu Indra, cujo significado também é esmagador, que tem no avéstico vazra- um paralelo, adentrou o idioma finlandês na forma vasara, martelo, e no mordiviano užer, machado (WEST, 2007, p. 251). O que nos importa, aqui, é a constatação primeira de que houve uma importação, do Indo-Europeu para o FinoÚgrico, de palavras relacionadas ao martelo e ao machado que, como vimos, são indissociáveis das divindades atmosféricas Indo-Europeias.

Surpreendentemente, o cognato etimológico mais próximo do étimo mjölnir se dá no dialeto izhma, falado pelos povos Komi-Zyrianos, Fino-Úgricos que habitam sobretudo a região do extremo nordeste da Rússia, no Oblast de Murmansk: entre eles, as palavras molńi e molńij significam raio (KONAKOV et al., 2003, p. 96). Contudo, considerando a proximidade entre os Komi-Zyrianos e os eslavos ocidentais, é muito mais provável que essa palavra tenha sido inserida em seu vocabulário por meio de importação da palavra russa mólnija (молния), que designa os raios e que inclusive pode, conforme vimos, ter exercido influências sobre o próprio nome e significado de mjölnir. Relevante é notar que essa constatação entrelaça, numa grande rede, os eslavos ocidentais aos nórdicos (ainda que não seja possível saber quem, de fato, teria influenciado quem), passando, nesse caminho, por povos não Indo-Europeus, como os Komi-Zyrianos. A conjectura que vislumbramos aqui é, portanto, de enormes proporções.

\section{Considerações Finais}

Após uma investigação das direções para onde aponta a etimologia de mjölnir, o martelo de Thor, podemos levantar alguns pontos relevantes. Longe de conclusões definitivas, o que se apresentam para nós são questões dignas de maiores investigações, que consistem em campos férteis para futuras pesquisas. Primeiramente, vimos a importância que mjölnir tinha na sociedade nórdica medieval a nível simbólico e mitológico, algo acusado pelas próprias fontes vernaculares que tratam do assunto, além da evidência oriunda da cultura material. Também ponderamos que o substantivo 
ISSN 1982-8713

que o designa nas fontes literárias, hammar, é passível de outras interpretações que não o martelo: talvez a princípio fosse concebido como uma pedra de raio que, com o passar do tempo, tenha se transformado em um machado feito de pedra.

Constatamos que mjölnir possui inúmeros paralelos, que se estendem da Escandinávia até a Rússia, passando por povos celtas, bálticos e outros germânicos. Ainda mais importante, pudemos elencar como as mitologias Indo-europeias estão repletas de divindades atmosféricas portando armas análogas à de Thor - também possivelmente sendo concebidas como sendo o próprio raio - com as quais eliminam inimigos monstruosos: esses paralelos são identificados em divindades da Síria, Irã, Índia, Grécia, Roma, Anatólia e muitas outras. Ao que parece, o mjölnir de Thor faz parte de uma concepção maior, de herança Indo-Europeia, que parece ter persistido desde um substrato muito antigo - talvez remetendo ao proto-Indo-Europeu - até o medievo de inúmeras culturas: um fenômeno de longue durée de considerável força pulsante e capacidade de amplitude. Essa concepção, conforme nos revelou o étimo de mjölnir, consiste em alocar, nas mãos de suas divindades atmosféricas, armas que, se por um lado, captam a ideia de arremesso dos raios e representam sua ida desde os céus até a terra, por outro, carregam a noção de que eles esmagam e pulverizam - conforme abordamos, as concepções não parecem ser excludentes, mas coexistentes -. A força dessa concepção é tamanha que mostrou ter tido aderência até mesmo por parte de povos Fino-Úgricos, que não tem, em suas concepções vernaculares de divindades do trovão, essa ideia do esmagamento. Mais do que teorias difusionistas, precisamos de pesquisas que tracem diacronicamente esse tipo de fenômeno e, em seguida, tentem compreender como ele transitou entre áreas, períodos históricos e povos diferentes, para além das fronteiras étnicas. 
ISSN 1982-8713

\section{Referências Bibliográficas}

\section{Documentação}

ANÔNIMO. The Poetic Edda. Translated and with notes by Caroline Larrington. Oxford: Oxford World's Classics, 2014.

GRAMMATICUS, Saxo. Gesta Danorum: The History of the Danes. Edited by Karsten FriisJensen and translated by Peter Fisher. Oxford: University Press, 2015.

STURLUSON, Snorri. The Prose Edda. Translated and with an introduction by Anthony Faulkes. Great Britain: Everyman, 1995.

\section{Bibliografia}

ALVES, Victor Hugo Sampaio. Diferentes sons do trovão: uma perspectiva comparativa entre os deuses Thor, Ukko e Horagalles. Dissertação de mestrado em Ciências da Religião. Universidade Federal da Paraíba, 2019, 219 p.

BLINKENBERG, Christian. The thunderweapon in religion and folklore: a study in comparative archaeology. Cambridge: University Press, 1911.

CAMERON, Averil. Procopius and the Sixth Century. London: Routledge, 2005.

CLEASBY, Richard; VIGFUSSON, Gudbrand. An Icelandic-English Dictionary. Oxford: Clarendon Press, 1874.

DAVIDSON, Hilda Ellis. Gods and myths of Northern Europe. London: Penguin Books, 1990.

DAVIDSON, Hilda Ellis. Thor's hammer. Folklore, n. 76, v. 1, 2015, p. 1-15.

DUMÉZIL, Georges. Gods of the Ancient Northmen. California: University of California Press, 1973.

DUVAL, Paul-Marie. Taranis. In: BONNEFOY, Ives (Org.). American, African and Old European Mythologies. Chicago: University of Chicago Press, 1993, p. 224.

FROG. Language and Mythology: Semantic Correlation and Disambiguation of Gods as Iconic Signs. In: MÁTTÉFFY, Attila (eds.); SZABADOS, György (eds.). Shamanhood and Mythology: Archaich Techniques of Ecstasy and Current Techniques of Research. Budapest: Hungarian Association for the Academic Study of Religions, 2017, p. 85-135.

FROG. Germanic traditions of the theft of the thunder-instrument (ATU 1148B): an approach to Prymskviða and Pórr's adventure with Geirrøðr in a circum-baltic perspective. In: HEIDE, Eldar (ed.); BEK-PEDERSEN, Karen (ed.). Resuming 
Methodological Discussions: Case Studies from Northern Europe Academia. Helsinki: Scientiarum Fennica, 2014, p. 120-162.

FROG. Circum-Baltic mythology? The strange case of the theft of the thunder instrument (ATU 1148 b). Archaeologia Baltica, n. 15, 2011, p. 78-99.

GRAHAM-CAMPBELL, James. Os Viquingues: origens da cultura escandinava, v. 1. Madrid: Del Prado, 1984.

GRIMM, Jacob. Teutonic Mythology, v. 1. London: George Bell and Sons, 1882.

HOLMBERG, Uno. The mythology of all races, v.IV: Finno-Ugric, Siberian. New York: Cooper Square Publishers, 1964.

KONAKOV, Nikolaĭ Dmitrievich et al. Encyclopaedia of Uralic Mythologies: Komi Mythology. Budapest: Akadémiai Kiadó, 2003.

KRAPPE, Alexander Haggerty. Picus who is also Zeus. Mnemosyne, v. 9, 1941, p. 241257.

KULMAR, Tarmo. On Supreme Sky God from the Aspect of Religious History and Prehistoric Estonian Material. Electronic Journal of Folklore, n. 31, 2005, p. 15-30.

LANGER, Johnni. Edda Poética. In: LANGER, Johnni (org.). Dicionário de Mitologia Nórdica: símbolos, mitos e ritos. São Paulo: Hedra, 2015, p. 146-149.

LANGER, Johnni. Edda em Prosa. In: LANGER, Johnni (org.). Dicionário de Mitologia Nórdica: símbolos, mitos e ritos. São Paulo: Hedra, 2015, p. 143- 145.

LANGER, Johnni. Martelo de Thor. In: LANGER, Johnni (org.). Dicionário de Mitologia Nórdica: símbolos, mitos e ritos. São Paulo: Hedra, 2015, p. 496 - 503.

LINDOW, John. Thor's hammar. Journal of English and Germanic Philology, n. 33, v. 4, 1994, p. 485-503.

MACKILLOP, James. A Dictionary of Celtic Mythology. Oxford: University Press, 2016.

MONTELIUS, Oscar. The Sun'God's Axe and Thor's Hammer. Folklore, n. 21, v. 1, p. 6078.

MOTZ, Lotte. The Germanic thunderweapon. Saga-Book n. 24, v. 5, 1997, p. 329-350.

NORDEIDE, Sæbjørg Walaker. Thor's hammer in Norway: a symbol of reaction against the Christian cross?. In: JENNBERT, Kristina (org.); ANDRÉN, Anders (org.); RAUDVERE, Catharina (eds.). Old norse religion: long-term perspectives: origins, changes and interactions. Lund: Nordic Academic Press, 2006, p. 218-222.

PERKINS, Richard. Thor the wind-raiser and the Eyrarland image. London: Viking Society for Northern Research, 2001. 
PUENTE, Inés García de la. Relato de los años pasados (PVL). In: NÚÑEZ, Juan Antonio (eds. e coord.). Fuentes para el studio de la religion eslava precristiana. Zaragoza: Libros Pórtico, 2017, p. 235-267.

PUHVEL, Jaan. Comparative Mythology. United States : Hopkins University Press, 1989.

RAVILIOUS, Kate. Thor's hammar found in Viking graves. National Geographic News, 2010. Disponível em: http://news.nationalgeographic.com/news/2010/08/100810thor-thors-hammer-viking-graves-thunderstones-science/

SALO, Unto. Ukko: the God of Thunder of the Ancient Finns and his Indo-European Family. Turku: Journal of Indo-European Studies, Monograph n. 51, 2006.

SALO, Unto. Agricola's Ukko in the light of archaeology: a chronological and interpretative study of the ancient Finnish Religion. Scripta Instituti Donneriani Aboensis, v. 13, 1990, p. $92-190$.

SCHJØDT, Jens Peter. Initiation Between Two Worlds: Structure and Symbolism in PreChristian Scandinavian Religion. Aarhus: The Viking Collection, 2008.

SHAW, John. The Dagda, Thor and ATU 1148B: Analogues, Parallels, or Correspondences?. Temenos, v. 55, n. 1, 2019, p. 97-120.

SIIKALA, Anna-Leena. Mythic Images and Shamanism: A Perspective on Kalevala Poetry. Helsinki: Academia Scientiarum Fennica: 2008.

SIMEK, Rudolf. Dictionary of Northern Mythology. Cambridge: D.S. Brewer, 2007.

TAGGART, Declan Ciaran. All mountains shake: seismic and volcanic imagery in the Old Norse literature of Pórr. Scripta Islandica, n. 68, 2017a, p. 99-121.

TAGGART, Declan. Stealing his thunder: an investigation of Old Norse pictures of Pórr. Saga-Book, n. 41, 2017b, p. 123-146.

TAGGART, Declan Ciaran. Understanding diversity in Old Norse religion: taking Pórr as a case study. Tese de doutorado em Filosofia. Universidade de Aberdeen, Escócia. 2015, $245 \mathrm{p}$.

TURVILLE-PETRE; Gabriel. Myth and Religion of the North: The Religion of Ancient Scandinavia. United States of America: Holt, Rinehart \& Winston, 1975.

TOLLEY, Clive. Shamanism in Norse myth and magic, vol.1. Helsinki: Academia Scientiarum Fennica, 2009.

VRIES, Jean de. Altnordisches etymologisches Wörterbuch. Leiden: E. J. Brill, 1977.

VRIES, Jean de. Altgermanische Religionsgeschichte, vol. I-II. Grundriss der germanischen Philologie. Berlin: de Gruyter, 1956. 
WAMERS, Von Egon. Hammer und Kreuz: Typologische Aspekte einer nordeuropäischen Amulettsite aus der Zeit des Glaubenswechsels. In: MÜLLER-WILLE, Michael (eds.). Rom und Byzanz im Norden, 1999, p. 83-107.

WATKINS, Calvert. How to Kill a Dragon: aspects of Indo-European Poetics. Oxford: University Press, 1995.

WEST, Martin Litchfield. Indo-European Poetry and Myth. Oxford: University Press, 2007.

WADYL, Sławomir; KUCYPERA, Paweł. Early Medieval miniature axes of Makarov's type 2 in the Baltic Sea Region. Archaeologia Lituana, v. 12, 2011, p. 122-130. 